Izha Anna. The role of the internal use of mineral water in the complex treatment of patients with chronic viral hepatitis $\mathrm{C}$ with concomitant non-alcoholic fatty liver disease. Journal of Education, Health and Sport. 2020;10(1):226-235. eISSN 2391-8306. DOI http://dx.doi.org/10.12775/JEHS.2020.10.01.025

https://apcz.umk.pl/czasopisma/index.php/JEHS/article/view/JEHS.2020.10.01.025

http://dx.doi.org/10.5281/zenodo.3785345

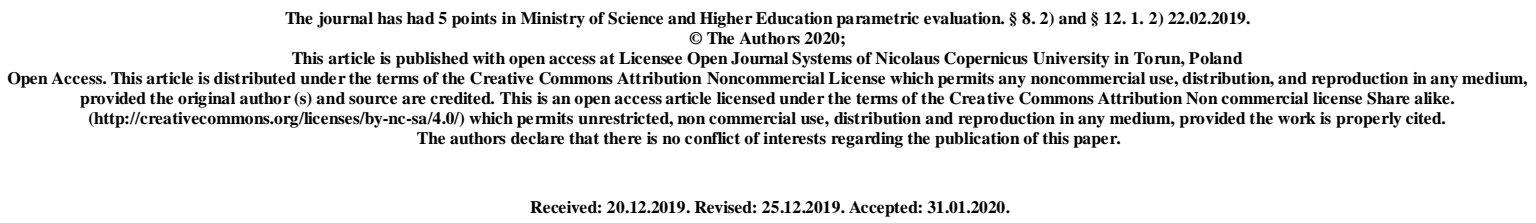

\title{
THE ROLE OF THE INTERNAL USE OF MINERAL WATER IN THE COMPLEX TREATMENT OF PATIENTS WITH CHRONIC VIRAL HEPATITIS C WITH CONCOMITANT NON-ALCOHOLIC FATTY LIVER DISEASE
}

\author{
Anna Izha \\ State Institution «Ukrainian Research Institute of Medical Rehabilitation and \\ Balneology of the Ministry of Health of Ukraine», Odessa, Ukraine
}

Abstract

Introduction: The use of modern drugs with direct antiviral effect allows achieving a stable virologic response (SVR) in patients with chronic hepatitis C (CHC). However, in most cases, after the elimination of $\mathrm{HCV}$ infection, the progression of fibrosis continues with the development of its terminal stages and adverse outcomes for patients. The presence of nonalcoholic fatty liver disease (NAFLD) in these patients significantly increases the rate of progression of fibrosis and its complications, even after reaching SVR. Therefore, the search and development of new non-drug treatment technologies for this category of patients is relevant. Aim: to study the effectiveness of mineral water intake (with a high content of bicarbonates, sodium, potassium, and silicon compounds) in the new mode of use in the complex treatment of patients with chronic hepatitis $\mathrm{C}$ with concomitant NAFLD. Methods: anamnestic, clinical, general clinical, biochemical (indicators of lipid metabolism, HOMA index), serological (markers of viral hepatitis C, HCV RNA PCR, qualitative and quantitative determination, genotyping), ultrasonographic studies of the digestive system and statistical methods. Results: Patients with chronic hepatitis $\mathrm{C}$ (genotype $1 \mathrm{~b}$ in the phase of replication, minimal and moderate activity) with concomitant NAFLD, which had been divided into two 
groups, were examined. Patients of group I (control group) received a standard complex of treatment (diet therapy that corresponded to the Mediterranean diet, dosed exercise regimen, antiviral therapy - sofosbuvir (400 mg) and ledipasvir (90 mg) - 3 months). Patients of group II (the main group) additionally received an internal course intake of mineral water (MW) according to our methodology: $3 \mathrm{ml}$ per $\mathrm{kg}$ of patient's body weight 30-40-60 min before meals, depending on the acidity in the stomach, and the same dose after food intake, three times a day (course - 2 months, a break - 2 months, a second course - 2 months). Evaluation of the effectiveness of treatment was carried out after six months from the start of treatment. Conclusion: The results prove the feasibility and effectiveness of using MW in a doubled dosage regimen in the complex treatment of patients with chronic hepatitis $\mathrm{C}$ with chronic concomitant NAFLD, which was determined by improving lipid metabolism, reducing signs of insulin resistance, improving ultrasonographic signs and preventing the development of fibrotic changes in the liver.

\section{Keywords: chronic viral hepatitis $\mathrm{C}$; non-alcoholic fatty liver disease; mineral} water.

\section{Introduction}

The problem of treatment of chronic hepatitis $C$ is one of the most discussed topics in gastroenterology and hepatology, which is associated primarily with the high specific gravity of chronic hepatitis $\mathrm{C}$ in the structure of chronic liver diseases both in Ukraine and abroad [1, 2]. The most common virus $C$ genotype in Ukraine is $1 \mathrm{~b}$. As before, the highest incidence rates have been recorded among people of working age. $\mathrm{CHC}$ is one of the leading causes of liver cirrhosis with the development of hepatic cell failure and hepatocellular carcinoma, which increases the risk of death.

For a long time, a combination of pegylated interferon alpha (peg-IFN $\alpha$ ) and ribavirin has been using as a standard for the treatment of chronic hepatitis C. However, standard dual therapy was effective only in $40-50 \%$ of patients; moreover, it was often accompanied by severe adverse events that impeded treatment. Advances in molecular biology in the study of the hepatitis $\mathrm{C}$ virus have facilitated the development of direct-acting antiviral drugs (DAAs) for the treatment of chronic hepatitis $\mathrm{C}$. The experience of using DAAs in real clinical practice has shown a high frequency of pathogen elimination; however, chronic hepatitis $\mathrm{C}$ is a systemic disease that requires an individual approach taking into account comorbid liver pathology $[3,4]$. 
According to modern concepts, many factors affect the natural course of chronic hepatitis $\mathrm{C}$ and the effectiveness of antiviral treatment. Two groups are considered among them: virus factors - the genotype of HCV infection, the variability of the virus genome, and patient factors - age, gender, race, alcohol abuse, co-infection with other viruses, and concomitant liver pathology $[5,6,7,8]$. The possibility of developing NAFLD with chronic $\mathrm{HCV}$ infection is significantly higher than with other liver diseases. It is diagnosed two times more often than with chronic HCV infection and autoimmune hepatitis. The presence of fatty liver infiltration in patients with chronic hepatitis $\mathrm{C}$ hurts the rate of progression of $\mathrm{HCV}$ infection and reduces the effectiveness of even modern DAAs $[9,10,11]$.

Mineral waters (MW) of various chemical composition are successfully used in the treatment of diseases of the gastrointestinal tract, hepatobiliary system, metabolism, etc., due to the peculiarities of their physicochemical composition, osmolarity, the presence of biologically active substances and compounds, affinity (similarity) with the buffer systems of the body. Also, when macro- and microelements enter the body as part of MW, their therapeutic dose is several times less (that is, more effective) than in pharmaceutical preparations, which determines the diversity of the effectiveness of their biomedical effects [12-16].

Analyzing the literature data, we found that MW with a sufficient content of bicarbonates, chlorine, sodium, potassium ions, and trace elements have lipid-lowering, hepatotropic, and cardioprotective properties, which is pathogenetically substantiated in the treatment of patients with chronic hepatitis C with concomitant NAFLD [17-21].

Meanwhile, there is almost no robot dedicated to the rationale for the use of MW in patients with chronic hepatitis $\mathrm{C}$ with concomitant NAFLD. Therefore, the study of the therapeutic effect of a unique natural factor - MW in patients with chronic hepatitis $\mathrm{C}$ with concomitant NAFLD is advisable.

The aim of the work is to evaluate the effectiveness of low-saline silicon bicarbonate sodium MW in the new mode of use in the complex treatment of patients with chronic hepatitis $\mathrm{C}$ with concomitant NAFLD.

Materials and methods. Based on the outpatient department of SI "Ukr. Research Institute of MR and K of the Ministry of Health of Ukraine" and the clinical sanatorium “Arcadia"of the State Border Service of Ukraine, 52 patients with chronic hepatitis C (genotype $1 \mathrm{~b}$ in the replication phase, minimal and moderate degree of activity) with concomitant NAFLD were examined. 
The research used methods such as anamnestic and clinical (gastroenterological examination in which the severity of pain, dyspeptic, asthenic syndromes was assessed based on the study of subjective and objective signs of the disease), a study of general clinical, biochemical blood parameters, including lipid metabolism, was evaluated IR according to the HOMA index, an ultrasonographic study (ultrasound) of the digestive system. The obtained results were processed by the generally accepted methods of variation statistics, the average values, their errors, and the Fisher-Student t-test were calculated.

At the beginning of the study, we formed two groups of patients with chronic hepatitis C with concomitant NAFLD. Patients of group I (22 patients, control group) received a standard complex of treatment (diet therapy that corresponded to the Mediterranean diet (12), dosed exercise regimen, antiviral therapy - sofosbuvir (400 mg) and ledipasvir (90 mg) - 3 months). Patients of group II (30 people, the main group) additionally received an internal course of MB according to the method developed by us: $3 \mathrm{ml}$ per $\mathrm{kg}$ of patient's body weight 30-40-60 minutes before meals, depending on the acidity in the stomach, and the same dose after administration food three times a day (course - 2 months, a break - 2 months, a second course - 2 months).

We used packaged silicon low-mineralized bicarbonate sodium water of well No. 242 , the village of Shayan, Khust district of the Transcarpathian region (Ukraine). The total mineralization of MW was $1.86 \mathrm{~g} / 1$. The main anions in the chemical composition of MW were $\mathrm{HCO}_{3}^{-}(1.187 \mathrm{~g} / \mathrm{l}), \mathrm{Cl}^{-}(0.095 \mathrm{~g} / \mathrm{l})$, and among the cations, $\mathrm{Na}+$ and $\mathrm{K}+$ ions $(0.447 \mathrm{~g}$ / 1). Other cations and anions $-\mathrm{SO}_{4}{ }^{2-}(0.059 \mathrm{~g} / \mathrm{l}), \mathrm{Ca}^{2+}(0.064 \mathrm{~g} / \mathrm{l})$ and $\mathrm{Mg}^{2+}(0.008 \mathrm{~g} / \mathrm{l})$ had insignificant concentrations. In MW, there are biologically active components and compounds that are standardized in balneology according to the legislation of Ukraine [16], and add specific properties to waters. Such components are $\mathrm{H}_{2} \mathrm{SiO}_{3}$ (metasilicic acid) - 69.42 mg / 1 (silicones are considered MW with an $\mathrm{H}_{2} \mathrm{SiO}_{3}$ content of $50 \mathrm{mg} / 1$ and $\mathrm{H}_{3} \mathrm{BO}_{3}$ (Orthoboric acid) - $15.83 \mathrm{mg} / \mathrm{l}$ (boric ones are MW with an $\mathrm{H}_{3} \mathrm{BO}_{3}$ content from $35 \mathrm{mg} / \mathrm{l}$ ).

Evaluation of the effectiveness of treatment was carried out six months after the start. Before treatment, $84.6 \%$ of patients had signs of the asthenic syndrome - fatigue, weakness, sleep disturbance, irritability. Manifestations of the dyspeptic syndrome were identified in $48.0 \%$ of patients. Among the signs characterizing abdominal pain syndrome, pain, or a feeling of heaviness in the right hypochondrium dominated were $55.7 \%$ of the examined. Complaints of pain in large and small joints are signs of the arthralgic syndrome, were identified in $34.6 \%$ of patients. 
An objective examination most often determined soreness on palpation of the right hypochondrium - $61.5 \%$ of cases, a little less often determined soreness in the left hypochondrium $-42.3 \%$ of cases. Hepatomegaly was present in $65.3 \%$ of patients.

The vast majority of patients were overweight or obese I-II degrees. (BMI was equal to an average of $31.62 \pm 1.24 \mathrm{~kg} / \mathrm{m}^{2}$ ).

The study of a general blood test determined an increase in the level of lymphocytes, monocytes, and ESR in 46.1\%, 36.5\%, and $21.1 \%$ of people, respectively. All other hemogram indices for the entire group of patients were within typical values.

When conducting a biochemical study of blood serum at the beginning of treatment, most patients showed impaired liver function. Among the examined patients, the phenomena of cytolytic syndrome dominated $-63.4 \%$ of cases. In $46.1 \%$ of patients, the level of alkaline phosphatase was increased to $1.5 \mathrm{~N}$, and gamma-glutamate transferase to $2 \mathrm{~N}$. In $40.3 \%$ of patients, the thymol test was increased (the average was $(7.03 \pm 0.95 \mathrm{u})$.

All patients had signs of dyslipidemia. They were characterized by an increase in the level of total cholesterol (TC) on average to $(6,83 \pm 0,19) \mathrm{mmol} / \mathrm{l}$, the level of triglycerides $(2,14 \pm 0,14) \mathrm{mmol} / \mathrm{l}$, low-density lipoproteins (LDLs averaged up to $(4.05 \pm 0.28) \mathrm{mmol} / \mathrm{l}$, decreasing levels of high-density lipoproteins (HDLs) in the group average to $(1.52 \pm 0.16)$ $\mathrm{mmol} / \mathrm{l}$. The atherogenic coefficient was on average $(4.58 \pm 0.32)$ units. The plasma glucose level on average was $(6.51 \pm 0.39) \mathrm{mmol} / \mathrm{L}$, the insulin concentration was slightly increased and averaged $(18.64 \pm 0.97) \mu \mathrm{U} / \mathrm{ml}$. At the same time, the HOMA index was $(5.38 \pm 0.43)$ units, which indicates a pronounced IR in the examined patients.

All patients showed active replication of HCV infection in serum according to PCR. So, in $55.7 \%$ of patients, a low level of the virological load was determined, and in $44.2 \%$ of the examined patients, a high level of virological load (> $800000 \mathrm{IU} / \mathrm{ml}$ ) was diagnosed.

According to ultrasound data, in $100 \%$ of patients, sonographic signs of hepatic steatosis were determined (distal attenuation of the echo signal, blurred vascular pattern, diffuse increase in the "brightness" of the hepatic parenchyma). Hepatomegaly was identified in $67.3 \%$ of the examined. In $63.4 \%$ of patients, signs of chronic non-calculous cholecystitis were detected in the form of thickening and compaction of the walls of the bladder, an increase in its echogenicity. $42.3 \%$ of patients had signs of chronic inflammation of the pancreas in the form of an uneven rise in echogenicity, fuzzy contours, heterogeneity of its parenchyma.

After the proposed complex treatment, the overwhelming majority of patients in both groups improved overall well-being, significantly increased the severity of subjective and 
objective signs of the underlying disease, improved liver function, and ultrasonographic picture of the hepatopancreatobiliary system. But, an analysis of the results showed some differences between groups of patients.

During treatment in patients of both groups, an improvement in the clinical course of the disease was noted, which was confirmed by the leveling of signs of asthenic ( $p<0.001$ ) and pain abdominal syndromes $(\mathrm{p}<0.001)$. Elimination of manifestations of dyspeptic syndrome (bitterness in the mouth, nausea, flatulence), significant dynamics ( $p$ <0.001) was determined in patients of group II, in contrast to patients in the control group ( $p>0.5)$.

An anthropometric study of all examined revealed a significant $(\mathrm{p}<0.001)$ decrease in body weight. At the end of treatment, the average BMI for two groups was - $(25.39 \pm 1.18) \mathrm{kg}$ $/ \mathrm{m} 2$.

Six months after the start of treatment, there was a significant $(\mathrm{p}<0.001)$ normalization of ESR and lymphocyte levels in patients with an initially elevated level of these indicators. There was also a significant $(p<0.001)$ decrease in the number of patients with monocytosis. At the end of treatment, their percentage was $13.4 \%$ of people versus $36.5 \%$ of people at the beginning of treatment.

Analysis of biochemical parameters determined reliable $(p<0.001)$ elimination of signs of cytolytic and cholestatic syndromes and normalization of the level of thymol test in patients of groups I and II. However, it should be noted that the normalization of the above indicators occurred at three months of treatment in patients of group II, in contrast to patients of group I, in whom the dynamics were slower and was observed, on average, at five months from the start of treatment.

During treatment, normalization of the blood lipid spectrum and indicators of carbohydrate metabolism was achieved in patients of the main group, in contrast to patients in the control group. So, in patients of group II, a reliable dynamics of decreasing the concentration of TC $((6.69 \pm 0.14) \mathrm{mmol} / \mathrm{l}-$ before treatment and $(5.33 \pm 0.22) \mathrm{mmol} / \mathrm{l})$ after treatment was determined, $\mathrm{p}<0.001$, B-lipoproteins $((65.14 \pm 2.09)$ units - before treatment and $(54.27 \pm 2.15)$ units after treatment, $\mathrm{p}<0.001)$, triglycerides $((2.18 \pm 0.17)$ mmol / 1 - before treatment and after treatment (1.69 \pm 0.13$) \mathrm{mmol} / \mathrm{l}, \mathrm{p}<0.02)$, LDL $((4.54 \pm$ $0.23) \mathrm{mmol} / \mathrm{l}$ - before treatment and after treatment $(2,58 \pm 0.27) \mathrm{mmol} / \mathrm{l}, \mathrm{p}<0.001)$, HDL $((1.24 \pm 0.13) \mathrm{mmol} / \mathrm{l}$ - before and after treatment $(1.65 \pm 0.12) \mathrm{mmol} / \mathrm{l}, \mathrm{p}<0.001)$.

The dynamics of the signs of IR in patients of the main group showed an explicit dynamics of the HOMA-IR index, which, to a greater extent, was due to a decrease in insulin concentration, especially in patients with basal hyperinsulinemia. 
Analysis of the results of a study of the dynamics of qualitative determination of HCV PCR RNA, carried out after 1, 3, and 6 months from the start of treatment, determined the presence of virological response in all examined.

The study of ultrasound data of the abdominal cavity organs determined the predominant dynamics of the improvement of the hepatopancreatobiliary zone in patients of the main group. So, in patients of group II, after six months from the start of treatment, a tendency was found to decrease the acoustic density of the liver parenchyma and decrease the size of inflammatory foci, improve the passage of the echo signal into the deeper layers of the liver, and improve the visualization of the vessels of the organ. In patients with concomitant lesions of the gallbladder, the appearance of a homogeneous content or a significant decrease in sediment in the gallbladder was observed against the background of a significant reduction in the volume of the gallbladder under conditions of its initial increase - $(7.81 \pm 0.52) \mathrm{cm} 3$ at the end of treatment versus $(9.46 \pm 0.61) \mathrm{cm} 3$ at the beginning of treatment $(p<0.05)$. In contrast, in patients of the control group, significant changes in the ultrasound picture did not $\operatorname{occur}(\mathrm{p}>0.05)$.

Thus, the obtained results prove the advisability of using MW in a doubled dosage regimen in the complex treatment of patients with chronic hepatitis $\mathrm{C}$ with chronic concomitant NAFLD to restore lipid metabolism, reduce signs of insulin resistance, and improve ultrasonographic signs. The proposed treatment affects the main pathogenetic links in the formation and progression of NAFLD to increase the effectiveness of therapy for the underlying disease and prevent the development of fibrotic changes in the liver.

\section{Conclusions}

1. In patients with CVHC with concomitant NAFLD, the clinical signs of asthenic $(84.6 \%)$ and pain abdominal $(55.7 \%)$ syndromes, impaired liver function (presence of cytolytic (63.4\%), and cholestatic (most often) 46.1\%), mesenchymal-inflammatory (40.3\%) syndromes), all examined were diagnosed with signs of dyslipidemia and IR along with changes in ultrasound data - distal attenuation of the liver echo (100.0\%) and hepatomegaly $(67.3 \%)$

2. The combined use of diet therapy, exercise, standard AVT in patients with chronic hepatitis $\mathrm{C}$, with concomitant NAFLD, significantly $(\mathrm{p}<0.001)$ reduces the clinical signs of asthenic and abdominal pain syndromes. It normalizes the functional state of the liver by eliminating the signs of cytolytic, cholestatic and mesenchymal-inflammatory syndromes ( $p$ $<0.001)$. It leads to a virological response in all patients of this group. 
3. The combined use of diet therapy, physical activity, standard PVT, GO in a doubled dosage regimen contributes to reliable $(\mathrm{p}<0.001)$ elimination of clinical signs of the underlying and concomitant diseases, normalization of the liver's functional state, especially lipid profile and IP, the primary biochemical markers of NAFLD. Significantly $(p<0.05)$, the ultrasound picture of the digestive system is restored and leads to a virological response in all patients in this group.

\section{References}

1. Zaytsev I, Potii V, Kiriienko V. Possible strategies for the implementation of WOH Program on the elimination of hepatitis C in Ukraine by 2030. Journal of Education, Health and Sport. 2018;8(6):324-335. Available from: http://www.ojs.ukw.edu.pl/index.php/johs/article/view/5602.

2. Stanaway J.D, Flaxman AD, Naghavi M. et al. The global burden of viral hepatitis from 1990 to 2013: findings from the Global Burden of Disease Study 2013. The Lancet. 2016 Sep; 388 (10049): 1081-1088. doi: 10.1016/S0140-6736(16)30579-7.

3. Klimova EA, Burnevich EZ, Chulanov VP. et al. Efficacy and safety of narlaprevir/ritonavir and daclatasvir non interferon combination in population of Russian patients with chronic hepatitis C. Terapevticheskii arkhiv. 2019;(8):67-74. doi: 10.26442/00403660.2019.08.000384.

4. Bailly F, Pradat P, Virlogeux V, Zoulim F. Antiviral therapy in patients with hepatitis C virus-induced cirrhosis. Dig Dis. 2015;33(4):613-23.doi:10.1159/000375359.

5. Lapa D, Garbuglia AR, Capobianchi MR, Del Porto P. Hepatitis C Virus Genetic Variability, Human Immune Response, and Genome Polymorphisms: Which Is the Interplay? Cells. 2019 Apr; 8(4): 305. doi: 10.3390/cells8040305.

6. Mallat A, Hezode C, Lotersztajn S. Environmental factors as disease accelerators during chronic hepatitis C. Journal of Hepatology. 2008;48(4): 657-665. https://doi.org/10.1016/j.jhep.2008.01.004.

7. Niu ZL, Zhang PA, Tong YQ. Age and gender distribution of Hepatitis C virus prevalence and genotypes of individuals of physical examination in WuHan, Central China. Springerplus. 2016; 5(1): 1557. doi: 10.1186/s40064-016-3224-z.

8. Esfeh JM, Ansari-Gilani K. Steatosis and hepatitis C. Gastroenterol Rep (Oxf). 2016 Feb; 4(1): 24-29. doi: 10.1093/gastro/gov040. 
9. Bondini S, Younossi ZM. Non-alcoholic fatty liver disease and hepatitis C infection. Minerva Gastroenterol Dietol. $2006 \quad$ Jun;52(2):135-43. https://www.ncbi.nlm.nih.gov/pubmed/16557185

10. Kralj D, Jukić LV, ljević SS, Duvnjak M, Smolić M, Čurčić IB. Hepatitis C Virus, Insulin Resistance, and Steatosis. J Clin Transl Hepatol. 2016;4(1):66-75. doi: 10.14218/JCTH.2015.00051.

11. Adinolfi LE, Rinaldi L, Guerrera B. et al. NAFLD and NASH in HCV Infection: Prevalence and Significance in Hepatic and Extrahepatic Manifestations. International Journal of Molecular Sciences. - 2016; 6 (17): 803. doi: 10.3390/ijms17060803.

12. Quattrini S, Pampaloni B, Brandi ML. Natural mineral waters: chemical characteristics and health effects. Clin Cases Miner Bone Metab. 2016;13(3):173-180. doi: 10.11138 / ccmbm / 2016.13.3.173.

13. Zolotareva TA, Babov KD, Nasibullin BA, Kozjavkin VI, Torohtin AM, Jushkovskaja OG. [Medical rehabilitation] Medicinskaja reabilitacija. K.: KIM; 2012. 496 s. [in Russian].

14. Mennuni G, Petraccia L, Fontana M et al. The therapeutic activity of sulphatebicarbonate-calcium-magnesiac mineral water in the functional disorders of the biliary tract. Clin Ter. 2014;165(5):e346-52. doi: 10.7417/CT.2014.1761.

15. Gushcha S.G., Nasibullin B.A., Zukow W., Volyanska V.S. Influence of mineral water on the structural and functional state of the rats kidneys with metabolic syndrome. Journal of Education, Health and Sport. 2019;9(10):11-21. doi: http://dx.doi.org/10.5281/zenodo.3466125.

16. Nassini R, Andrè E,Gazzieri D, De Siena G, Zanasi A,Geppetti P, Materazzi S. A bicarbonate-alkaline mineral water protects from ethanol-induced hemorrhagic gastric lesions in mice. Biol Pharm Bull. 2010;33(8):1319-23. doi:10.1248/bpb.33.1319.

17. Gushcha Sergey, Dragomiretska Natalia, Zabolotna Iryna, Nasibullin Boris, Izha Anna, Badiuk Natalia, Koieva Khrystyna. Possibilities of using natural mineral waters in the treatment of patients with non-alcoholic fatty liver disease Balneo Research Journal. 2019. Vol. 10, № 4. P. 450 - 456. http://bioclima.ro/Balneo280.pdf.

18. Toxqui L, Vaquero MP. An Intervention with Mineral Water Decreases Cardiometabolic Risk Biomarkers. A Crossover, Randomised, Controlled Trial with Two Mineral Waters in Moderately Hypercholesterolaemic Adults. Nutrients. 2016;8(7):P. 400. doi:10.3390/nu8070400. 
19. Kolodenko OV, Gushha SG, Zukow W. Possibilities of balneotherapy in patients with coronary heart disease after surgical revascularization of myocardium with concomitant diabetes Journal of Education, Health and Sport. 2016;6()6.459-468. doi: http://dx.doi.org/10.5281/zenodo.56142. [in Ukrainan].

20. Gushcha SG, Nasibullin BA, Plakida AL, Volyanska VS, Gladkiy TV, Balashova IV. Hepatoprotective Action of Boric Mineral Waters in Toxic Hepatosis: Experimental Stady / Open Science Journal of Bioscience and Bioengineering. 2018;6(5):55-60. http://www.openscienceonline.com/journal/osjpp

21. Dragomiretskaya N. V., Zabolotnaya I. B., Migovich II. The therapeutic efficacy of natural medicinal resources in the treatment of patients with non-alcoholic fatty liver disease. Acta Balneologica. 2015;L VII, 4(142):253-256. http://actabalneologica.pl/wpcontent/uploads/2018/05/AB2015-4.pdf.

22. Mineral healing waters. State standard technical specifications 42.10-02-96. [Valid from 1996-06-24]. Kyiv: Ministry of Health of Ukraine. 1996. 30 p. (Industry standard of Ukraine). 